\title{
Single Fraction versus Multiple Fraction Radiotherapy for treatment of painful bone metastases: A Prospective Study; Mansoura experience
}

\author{
Abeer Hussien Anter \\ Department of Clinical Oncology and Nuclear medicine, \\ Faculty of Medicine, Mansoura University
}

\begin{abstract}
Purpose: Assessment of pain response in patients with bone metastasis after treating with two radiation schedules and to compare toxicity profile in both arms.

Patients \& Methods: A prospective randomised study was designed to include 100 patients from May 2011 to May 2013. Patients with histopathologically proven primary malignancy having symptomatic secondary deposits to bone were selected for the study. Patients were randomised to 8 Gy in a single fraction (arm A) or 20 Gy in five fractions (arm B). Initial pain response was assessed using numeric rating scale, and compared using the same scale 3 months after completion of treatment. Acute toxicities were assessed using the radiation therapy oncology group criteria for adverse events

Results: Arm A comprised 51 patients while 49 patients were enrolled in Arm B. Baseline patient characteristics were comparable. Twelve patients were lost to follow-up. So the 3-month pain score assessment was completed by 88 of the 100 patients; A complete response was observed in $20.4 \%$ (18 patients) of the 88 patients, and partial response was observed in $54.5 \%$ (48 patients), for an overall response rate of $75 \%$ ( 66 of 88 patients); only $10 \%$ (9 patients) of the 88 patients had progression of pain. Mild Gl toxicity was noted in both arms but differences in two arms were not statistically significant $(p=0.45)$, no interruption of treatment was required because of side effects.

Conclusions: In our study, we found both the radiation fractionation schedules for palliative bone metastasis treatment is equally effective in pain control.

Keywords: Bone metastases • Fractionation • Palliative • Radiotherapy • Pain scores

(C) De Gruyter Open
\end{abstract}

\section{Introduction}

Metastatic bone disease is a commonly encountered problem in oncology practice. Many patients with cancer, though heavily treated, ultimately metastasise. One of the important sites of metastasis is bone. Bone metastases can cause severe and debilitating effects, including pain, pathological fracture, hypercalcaemia and spinal cord compression. [1]

Palliative external beam radiotherapy (EBRT) is an effective treatment option for pain control from symptomatic bone metastases. Multiple randomised controlled studies, meta-analyses, and systematic reviews have all shown equivalence in pain response between single fraction (SF) radiotherapy and multiple fraction (MF) radiotherapy in cancer patients with bone metastases from a variety of primary malignancies.[2, 3, $4,5,6,7]$.

Despite that high-level evidence, the use of single fractions for the management of painful bone metastases is not as widely practiced in the world as the evidence may suggest. This discordance between the results of randomised trials and patterns of practice has been highlighted in several practice-pattern surveys. [8, 9, 10]

Radiotherapy is usually given as an outpatient treatment, which requires daily hospital attendance at a specialised centre that may be some distance from the patient's home. A protracted course of RT may cause considerable problems for patients, especially those with poor performance status and limited life expectancy. It also increases the workload of the treatment centre. [11] A single fraction of treatment has the advantages that it is 
logistically much easier for patients and their families to arrange for 1 session rather than 10 daily sessions and that it has less impact on the timing of other treatments (e.g., systemic therapy) and lower treatment costs.[12]

\section{Aim of study}

The primary objective of the study is to compare the pain-relieving efficacy and acute toxicities of two frequently administered radiation treatment doses: $8 \mathrm{~Gy}$ administered in a single fraction or 20 Gy given in multiple fractions in patients with painful bone metastases.

\section{Patients and Methods}

This prospective, randomised study was conducted in Clinical Oncology and Nuclear Medicine Department, Mansoura University Hospital.

\section{Eligibility criteria:}

Eligibility criteria included patients of 18 years or older, histologically proven primary malignancy (breast / prostate / lung, /other), radiographic evidence of bone metastasis, pain corresponding to the area of bone metastasis, a Karnofsky performance status of at least 40. Patients were ineligible if the painful area had received prior radiation therapy, if there was pathologic fracture or impending fracture of the treatment site, or if there was planned surgical fixation of the bone. Patients with clinical or radiographic evidence of spinal cord or cauda equina compression and/or effacement were not eligible.

After written informed consent was obtained, eligible patients were randomly assigned (1:1) to receive either $8 \mathrm{~Gy}$ in a single fraction ( $\mathrm{arm} \mathrm{A}$ ) or $20 \mathrm{~Gy}$ in five fractions (Arm B).

Patients' pain was evaluated just before start of treatment using numeric rating scale (NRS): for assessment of pain intensity. Patients rate their pain on a 0-10 scale Patient was asked to mark his or her present pain intensity assuming 10 as worst pain and 0 to be no pain. Answers were recorded by the patient or by a caregiver if the patient was unable to do so. Then pain was graded accordingly into no pain (0), mild (1, $2,3)$, moderate $(4,5,6)$ and severe $(7,8,9,10)$. Then patients were planned for radiation treatment.

\section{Treatment}

Treatments to the spinal bones should be prescribed to the midvertebral body, with inclusion of at least one vertebral body above and below the painful vertebral body level or levels. Other sites should be prescribed as an applied dose for single incident fields and a midplane dose for opposed fields, taking into account the normal tissue tolerance of those structures included in the treated volume. Long bone lesions should be treated with at least a 2-cm margin proximal and distal to the radiographically evident abnormality. Simulation and verification films should be completed in all cases to document target localisation. Two-dimensional treatment planning was used for all bone metastases.

Pain and analgesic use were evaluated again using the same method 3 months after the end of RT. Telephone follow-up was attempted for patients who did not come back to the clinic after treatment.

Endpoints are defined as follows: Palliative response; a complete response was defined as having no pain at 3 months after radiotherapy, a partial response was defined as a pain score that was at least 2 points lower than the baseline score, a stable response was defined as a 1-point change in pain score (either worse or better), and progression was defined as a pain score that was at least 2 points higher than the baseline score.

Acute toxicities were assessed using the Radiation Therapy Oncology Group (RTOG) criteria for adverse events. Haematologic and gastrointestinal side effects of RT were recorded in both treatment arms.

Statistical analysis

We used the SPSS statistical software package, version 16.0, for data entry and statistical analysis. Chisquare and independent samples t-tests were used for comparison between the patient groups; logistic regression was used to evaluate the various associated factors. Mann-Whitney test was done for independent samples to compare pain response at 3 months and $\mathrm{Gl}$ toxicities. Statistical significance was considered at $p<$ 0.05 .

\section{Results}

Between May 2011 and May 2013, we randomly assigned 100 patients to a treatment group [51 to a single fraction (arm A) and 49 to 5 fractions of palliative RT (arm B)].

Patient characteristics were well balanced between the two arms (Table 1). Median age was 53 years (range 30-82) and 52 years (range 32-80) in arm A and arm B, respectively. Female patients were predominant in both arms (58.8\% in arm A, 59\% in arm B), patients with KPS score 40 and 50 were predominant in both the arms. Most of the patients had primary site of malignancy from breast and prostate $(70.5 \%$ in arm $\mathrm{A}$ and $63.3 \%$ 
in arm B). Most common metastatic sites were spine and pelvis in both arms [Table 1].

There was excellent patient compliance with completion of the initial pain assessment. All patients completed their scheduled course of RT without incident. The most common toxicities were gastrointestinal followed by haematological toxicity, no patient developed grade 4 acute toxicities in both arms (Table 2).

The pain score assessment was complete in 100 patients at the time of study entry. The 3-month pain score assessment was completed by 88 of the 100 patients; the reasons for missing pain score assessment at 3 months included patient death (4 patients), patient refusal (5 patients), not come for follow-up and could not be contacted (3 patients).

A complete response was observed in $20.4 \%$ (18 patients) of the 88 patients, and partial response was observed in $54.5 \%$ (48 patients), for an overall response rate of $75 \%$ (66 of 88 patients); only $10 \%$ (9 patients) of the 88 patients had progression of pain (Table 3 ).

In arm A, the 3-month complete pain relief was (18\%) versus $(22 \%)$ in arm B (statistically non-significant also there was insignificant difference for partial pain relief between two arms (56.8\% versus $52.2 \%$ ).

By logistic regression, patient's sex, primary tumour, RT site, and type of treatment (single-fraction versus. multifraction) did not have any significant effect on pain reduction. The only factor with a significant effect was age $(p=0.03)$.

\section{Discussion}

Two large multicentre randomised trials $(4,11)$ and a meta-analysis of 16 randomised trials (5) have found no significant difference in the probability of achieving pain relief with different fractionation schedules of localised RT in painful uncomplicated bone metastases. More recently, published results of a northAmerican multicentre trial [Radiation Therapy Oncology Group (RTOG) 9714] (12) and a meta-analysis of 12 randomised trials (2) have confirmed those findings. Our findings are also in agreement.

The overall response rate to palliative RT in our trial was $75 \%$, which was consistent with the results reported in the international literature. In the RTOG 97-14 trial (12), the overall response rate was also 66\%; in Dutch Bone Metastasis Study (11), the overall response rate was also $71 \%$.and in the systematic review by Sze et al. (2), the rate was $59-60 \%$. The complete response rate in our trial $(20.4 \%)$ was lower than that in either the Dutch $(35 \%)$ or the Working Party $(57 \%)$ trial and that in the systematic review (32-34\%), but it was
Table 1. Characteristics of the study population*

\begin{tabular}{|c|c|c|}
\hline Characteristic & Arm A $(n o=51)$ & Arm B (no = 49) \\
\hline $\begin{array}{c}\text { Sex } \\
\text { Male } \\
\text { Female }\end{array}$ & $\begin{array}{l}21 \\
30\end{array}$ & $\begin{array}{l}20 \\
29\end{array}$ \\
\hline $\begin{array}{l}\text { Age } \\
\text { Median } \\
\text { Range }\end{array}$ & $\begin{array}{c}53 \\
30-82\end{array}$ & $\begin{array}{c}52 \\
32-80\end{array}$ \\
\hline $\begin{array}{l}40 \\
50 \\
60 \\
70\end{array}$ & $\begin{array}{c}20 \\
17 \\
8 \\
6\end{array}$ & $\begin{array}{l}19 \\
16 \\
7 \\
7\end{array}$ \\
\hline $\begin{array}{c}\text { Primary tumours } \\
\text { Breast }\end{array}$ & 25 & 22 \\
\hline Prostate & 11 & 9 \\
\hline Lung & 7 & 7 \\
\hline Kidney, bladder & 3 & 4 \\
\hline Gastrointestinal & 3 & 4 \\
\hline Cervix & 1 & 1 \\
\hline Unknown & 1 & 1 \\
\hline Lymphoma & 0 & 1 \\
\hline $\begin{array}{c}\text { Sites of treatment } \\
\text { Spine }\end{array}$ & 20 & 19 \\
\hline Sacrum or pelvis & 18 & 17 \\
\hline Extremities & 9 & 9 \\
\hline Ribs & 3 & 3 \\
\hline Sternum & 1 & 1 \\
\hline $\begin{array}{l}\text { Worst pain score } \\
\begin{array}{c}\text { (NRS), } \\
<5 \\
5-6 \\
7-10\end{array}\end{array}$ & $\begin{array}{c}3 \\
12 \\
36\end{array}$ & $\begin{array}{c}3 \\
11 \\
35\end{array}$ \\
\hline
\end{tabular}

* KPS = Karnofsky performance status; NRS = numeric rating scale.

similar to the response rate in the RTOG 97-14 trial $(17 \%)$. This finding might be related to differences in the questionnaires used, the timing of the pain evaluation after RT, the definition of complete response, or the small number of patients in our trial.

In contrast, two studies differ slightly in results; a Canadian trial reported in abstract form indicated that 
Table 2. Toxicity of treatment *

\begin{tabular}{|c|c|c|c|c|c|c|c|c|}
\hline \multirow{3}{*}{ Type of toxicity } & \multicolumn{8}{|c|}{ Acute toxicity, No. of patients } \\
\hline & \multicolumn{4}{|c|}{ Arm A } & \multicolumn{4}{|c|}{ Arm B } \\
\hline & G1 & G2 & G3 & G4 & G1 & G2 & G3 & G4 \\
\hline GI & 6 & 3 & 1 & 0 & 9 & 4 & 1 & 0 \\
\hline Haematologic & 3 & 1 & 0 & 0 & 5 & 2 & 0 & 0 \\
\hline Lung & 0 & 1 & 0 & 0 & 2 & 2 & 0 & 0 \\
\hline CNS & 1 & 0 & 0 & 0 & 1 & 1 & 0 & 0 \\
\hline
\end{tabular}

${ }^{*} \mathrm{G}=$ grade; $C N S$ = central nervous system; $\mathrm{Gl}$ = gastrointestinal system

Table 3. Overall response to treatment at 3 months after treatment

\begin{tabular}{c|ccc}
\hline Parameter & Arm A(no = 44) & Arm B (no = 44) & Total (\%) \\
\hline \hline Overall response type & 8 & 10 & $18(20.5)$ \\
Complete & 25 & 23 & $48(54.5)$ \\
Partial & 6 & 7 & $13(14.8)$ \\
Stable & 5 & 4 & $9(10.2)$ \\
Progressive & & & \\
\hline
\end{tabular}

20 Gy given in 5 fractions was superior to 8 Gy in 1 fraction for painful bone metastases, despite significant pain relief in that trial $(46 \%$ multi-fraction versus $32 \%$ single fraction) (13). Roos et al. found better outcome in multiple fraction arm when $20 \mathrm{~Gy} / 5$ fractions were used. 8/1 was neither shown to be as effective as 20/5, nor was it statistically significantly worse. Outcomes were generally poorer for $8 / 1$, although the quantitative differences were relatively small. (14)

Most studies, including ours, found insignificant differences in radiation-related toxicity between SF and MF treatments $(12,17,22)$. On the other hand, only few studies showed a difference in radiation-related toxicities between previous two regimens (The RTOG 97-14 study).

The RTOG 97-14 study is one of the few studies that found a difference in radiation-related toxicities between SF and MF regimens while most studies, for example, Hartselle et al. (12) had not found significant differences in toxicity between SF and MF treatments. Also, this issue was confirmed in our study.

Some studies have reported variable responses to palliative RT in bone metastases from different primaries, especially breast and prostate cancer compared to lung cancer. $(4,11)$. We found no difference in that issue, but the number of patients in our trial was not large enough to properly test the issue (we had only 14 patients with a lung primary).

Despite the high-level evidence published in international literature, several practice-pattern surveys conducted among radiation oncologists in various countries have shown limited use of single fractions for bone metastases. Haddad et al. studied a Canadian specialised academic palliative RT programme and [8, $10,15]$ demonstrated that only one-third of palliative RT courses for bone metastases were prescribed using a single fraction (16). This may be due to strong preference of clinicians to use multiple fractions for spinal metastases afraid of complications of bone metastases such as sub-acute cord compression and pathologic fracture $(18,19,20)$.

The costs of radiotherapy can differ from site to site, but studies from three countries on three continents have consistently shown a cost-effectiveness advantage to SF regimens $(21,22,23,24)$. Healthcare costs should not play a disproportionate role in treatment decisions, but are still an important consideration, especially in developing countries like Egypt. 


\section{Conclusion}

In our study, we found both the radiation fractionation schedules for palliative bone metastasis treatment to be equally effective in pain control. These findings are in line with the present literatures. We think that a singlefraction RT for that purpose can be safely administered without any hesitation as supported by "high evidence" literatures. Our study also points to similar results. Saving of radiotherapy capacity was also considered a major economic advantage of the SF regimen.

\section{References}

[1] Agarawal JP, Swangsilpa T, van der Linden $Y$, Rades D, Jeremic B, Hoskin PJ. The role of external beam radiotherapy in the management of bone metastases. Clin Oncol (R Coll Radiol) 2006; 18:747-60.

[2] Sze WM, Shelley MD, Held I, Wilt TJ, Mason MD. Palliation of metastatic bone pain: single fraction versus multifraction radiotherapy a systematic review of randomised trials. Clin Oncol ( $R$ Coll Radiol).2003; 15(6):345-352.

[3] Chow E, Zeng L, Salvo N, Dennis K, Tsao M, Lutz S. Update on the systematic review of palliative radiotherapy trials for bone metastases. Clin Oncol (R Coll Radiol). 2012; 24(2):112-124..

[4] Bone Pain Trial Working Party. 8 Gy single fraction radiotherapy for the treatment of metastatic skeletal pain: randomized comparison with a multifraction schedule over 12 months of patient follow-up. Radiotherapy Oncol 1999; 52:111-21.

[5] Wu JS, Wong R, Johnston M, Bezjak A, Whelan $\mathrm{T}$, on behalf of the Cancer Care Ontario Practice Guidelines Initiative Supportive Care Group. Metaanalysis of dose-fractionation radiotherapy trials for the palliation of painful bone metastases. Int $\mathrm{J}$ Radiat Oncol Biol Phys 2003; 55:594-605.

[6] Chow E, Harris K, Fan G, Tsao M, Sze WM. Palliative radiotherapy trials for bone metastases: a systematic review. J Clin Oncol. 2007; 25(11):14231436.

[7] McQuay HJ, Collins SL, Carroll D, Moore RA. Radiotherapy for the palliation of painful bone metastases. Cochrane Database Syst Rev. 2000;(2):CD001793.

[8] Chow E, Danjoux C, Wong R, et al. Palliation of bone metastases: a survey of patterns of practice among Canadian radiation oncologists. Radiotherapy Oncol 2000; 56:305-14.

\section{Conflict of interest statement}

The authors declare no conflict of interest.

[9] Ben-Josef E, Shamsa F, Williams AO, Porter AT. Radiotherapeutic management of osseous metastases: a survey of current patterns of care. Int J Radiat Oncol Biol Phys 1998; 40:915-21.

[10] Roos DE. Continuing reluctance to use single fractions of radiotherapy for metastatic bone pain: an Australian and New Zealand practice survey and literature review. Radiother Oncol 2000; 56:31522.

[11] Steenland E, Leer JW, van Houwelingen $H$, et al. The effect of a single fraction compared to multiple fractions on painful bone metastases: a global analysis of the Dutch Bone Metastasis Study. Radiotherapy Oncol 1999; 52:101-9.

[12] Hartsell WF, Scott CB, Bruner DW, et al. Randomized trial of short- versus long-course radiotherapy for palliation of painful bone metastases. J Natl Cancer Inst 2005; 97:798-804.

[13] Kirkbride P, Warde P, Panzarella T, Aslanidis J, McKenzie M, Sun A. A randomized trial comparing the efficacy of a single radiation fraction with fractionated radiation therapy in the palliation of skeletal metastases [abstract]. Int J Radiat Oncol Biol Phys 2000; 48(suppl):185.

[14] Roos DE, Turner SL, O'Brien PC, Smith JG, Spry NA, Burmeister $\mathrm{BH}$, et al. Randomized trial of $8 \mathrm{~Gy}$ in 1 versus $20 \mathrm{~Gy}$ in 5 fractions of radiotherapy for neuropathic pain due to bone metastases (TransTasman Radiation Oncology Group, TROG 96.05). Radiother Oncol 2005; 75:54-63.

[15] Ben-Josef E, Shamsa F, Williams AO, Porter AT. Radiotherapeutic management of osseous metastases: A survey of current patterns of care. Int J Radiat Oncol Biol Phys 1998; 40:915-21.

[16] Haddad P, Wong RK, Pond GR, Soban F, Williams $D$, McLean $M$, et al. Factors influencing the use of single vs. multiple fractions of palliative radiotherapy 
for bone metastases: A 5-year review. Clin Oncol ( $R$ Coll Radiol) 2005; 17:430-4.

[17] Chow E, Lutz S, Beyene J. A single fraction for all, or an argument for fractionation tailored to fit the needs of each individual patient with bone metastases? Int J Radiat Oncol Biol Phys 2003; 55:565-7.

[18] Majumder D, Chatterjee D, Bandyopadhyay A, et al. Single Fraction versus Multiple Fraction Radiotherapy for Palliation of Painful Vertebral Bone Metastases: A Prospective Study Indian Journal of Palliative Care 2014; Vol-18 / Issue3:202-206

[19] Fairchild A, Barnes E, Ghosh S, et al. International patterns of practice in palliative radiotherapy for painful bone metastases: evidence based practice? Int J Radiat Oncol Biol Phys 2009;75:1281-1628.

[20] Janjan N, Lutz S, Bedwinek J, et al. Therapeutic guidelines for the treatment of bone metastasis: A report from the American College of Radiology Appropriateness Criteria Expert Panel on Radiation Oncology. J Palliative Medicine 2009; 12:417-426
[21] Konski A, James J, Hartsell W, et al. Economic analysis of radiation therapy oncology group 97-14: multiple versus single fraction radiation treatment of patients with bone metastases. Am J Clin Oncol.200 9; 32(4):423-428.

[22] Pollicino CA, Turner SL, Roos DE, O'Brien PC. Costing the components of pain management: analysis of Trans-Tasman Radiation Oncology Group trial (TROG 96.05): one versus five fractions for neuropathic bone pain. Radiother Oncol. 2005; 76(3):264-269.

[23] Van den Hout WB, van der Linden YM, Steenland E, et al. Single- versus multiple-fraction radiotherapy in patients with painful bone metastases: cost-utility analysis based on a randomized trial. J Natl Cancer Inst. 2003; 95(3):222-229.

[24] Konski A. Radiotherapy is a cost-effective palliative treatment for patients with bone metastasis from prostate cancer. Int J Rad Oncol Biol Phys. 2004;60(5):1373-1378. 